\title{
The Effect of Mesenchymal Stem Cells of Umbilical Cord on the Treatment of Cleft Palate in Children
}

\author{
Mobina Vatankhah \\ Farzanegan School, Bandar Abbas, Iran \\ Email: mobinavatankhah@gmail.com
}

How to cite this paper: Vatankhah, M. (2018) The Effect of Mesenchymal Stem Cells of Umbilical Cord on the Treatment of Cleft Palate in Children. CellBio, 7, 63-67. https://doi.org/10.4236/cellbio.2018.74006

Received: July 5, 2018

Accepted: December 21, 2018

Published: December 24, 2018

Copyright $\odot 2018$ by author and Scientific Research Publishing Inc. This work is licensed under the Creative Commons Attribution International License (CC BY 4.0).

http://creativecommons.org/licenses/by/4.0/

\begin{abstract}
Cleft palate or harelip is one of the most common congenital defects in humans and harelip with cleft lip in whites is estimated 1 out of every 7000 to 1000 births. In recent years, surgeons and doctors have tried to resolve this problem immediately after the birth by operation, but sometimes we encounter things that cannot be easily solved by a surgical procedure. Our goal is to use stem cells to eliminate the disease and prevent operation, because children are often afraid of surgery and pain later on. Also, the need for general anesthesia for bone remodeling involves complications, such as long-term pain and nerve disorders. By the advent of the use of alternative stem extraction techniques, a better alternative to the invasive method of cleft lip and palate therapy has been developed.
\end{abstract}

\section{Keywords}

Mesenchymal Stem Cells, Cleft Palate

\section{Introduction}

The cleft lip is a controversial issue that has led the world's leading medical and educational centers to achieve significant growth and prosperity. The oral-pink cleft is not the exception as the most common congenital anomaly in the craniofacial region. Bone graft as an alveolar cleft is an inseparable part of the process of treating patients with a one-way or two-way cleft lip and palate. The statistics show that in the United States of America, out of every 10 children, 6 children have oral-pectoris disorder. An annual cost of $\$ 200$ million is spent on the treatment of children with this malformation. This disease includes complications, such as speech impairment, nutrition, hearing loss, and repeated infec- 
tions of the ear and dental disorders. Surgery can fix the problem of cleft lip. Before surgery, the doctor may use special equipment and accessories, such as dental splints or medical bandages to protect the child and reduce his problems. Most doctors recommend that the baby undergoes surgery at the age of 6 months. However, the exact time of surgery is different for each infant and depends on a variety of factors, including the extent of the cleft lip and the overall health of the baby. The baby may have to undergo several other surgical procedures during the course of her growth. For example, if your baby's nasal appearance is affected by cleft lip, a nasal surgery may be advisable at a certain age. Due to the complications of these surgeries on the baby, physicians are looking for a more appropriate way to cure this disorder (Figure 1) [1]. In the recent decade, many articles on the extraction and cultivation of bone marrow stem cells for the treatment of this malformation have been published in the valid journals and magazines, but there are major problems in extracting these types of stem cells. Despite having these studies, it has not yet been possible to cultivate and inject these cells into the target tissue, because the extraction and cultivation of bone marrow stem cells is time-consuming and this abnormality should be treated urgently and at the earliest days of birth. Therefore, there is no time to extract and cultivate these cells. Extraction of these types of cells from bone marrow is a dangerous problem to children. So far, umbilical mesenchymal stem cells are the main cells of this extra-embryonic tissue [2]. These cells are similar to fibroblasts and form a base material, rich in proteoglycans, especially hyaluronic acid. These cell types are multi-potent and have similar features to the bone marrow cells, but they are faster and simpler to replicate, and they are better cells for the treatment of this abnormality. In this article, by extraction and cultivation of umbilical mesenchymal stem cells, better and safer treatment can be brought to children.

\section{Materials and Methods}

Separation of tissues containing MSSCS from the umbilical cord.

\subsection{Human}

The umbilical cord samples were collected from the Bandar Abbas Hospital in accordance with the ethical requirements of the research and with the consent of the mother after child birth [3].

The umbilical cord sample collected from the Bandar Abbas Hospital in accordance with the ethical requirements of the research and with the consent of the mother after childbirth and after transfer to sterilization room, the cultivating room was studied and examined.

To eliminate pollution, we place 70 percent of the cord in alcohol for 30 seconds. Then, to ensure that there is no blood in the specimens, we rinse it again by PBS. The cord is divided into $5 \mathrm{~mm}^{2}$ pieces by scissors, and then the pieces are arranged inside the plate $\left(10 \mathrm{~cm}^{2}\right.$ Brand) [4]. 
On the samples, $10 \mathrm{ml}$ of the culture medium (Dulbecco's Modified Medium:DMEM) was poured and plates were incubated in a BINDER incubator at $37^{\circ} \mathrm{C}$ and $5 \% \mathrm{CO}_{2}$ (Figure 1) [5].

The samples were examined each day under invert microscope (Figure 2). On the fifth day, they were replaced by half of their culture, and every three days thereafter, the substitution was carried out. On the twentieth day, cells filled $80 \%$ of the container. After this step, the cells were counted with Trypsin-EDTA, using Trypan Blue and Neubauer Lam, and transferred to new containers [6].

\subsection{MSSCs Differentiation into Jawbone Cells}

In order to confirm the mesenchymal nature of the cells investigated in this study, the distinctive property of differentiating cells into osteoblast cell washing by Alizarin Red was used. Third passage cells were selected and added to a number of flasks of the osteoblast differentiation medium instead of the DMEM medium. Their environment was changed every three days. The painting was carried out after 3 weeks and then examined (Figure 3).

\section{Results}

MSSCs were successfully isolated and cultured from human umbilical cord and injected into 10 infants over an intermittent therapy. After a year, this complication improved to a large extent, and the gap between the two lips was resolved, and with the continuity of treatment, the cleft palate of these babies was improving. According to the tests and studies, the extraction and culture of the mesenchymal stem cells from the cord takes less time. The amount of cells produced by this method is treated in this way up to $90 \%$ and without any side effects (Figure 4).

\section{Discussion}

This study, for the first time, investigates the amount of bone produced by autogenous bone tissue engineering. The results of the study indicated that although autogenous bone graft still has a golden standard of treatment for bone defects,

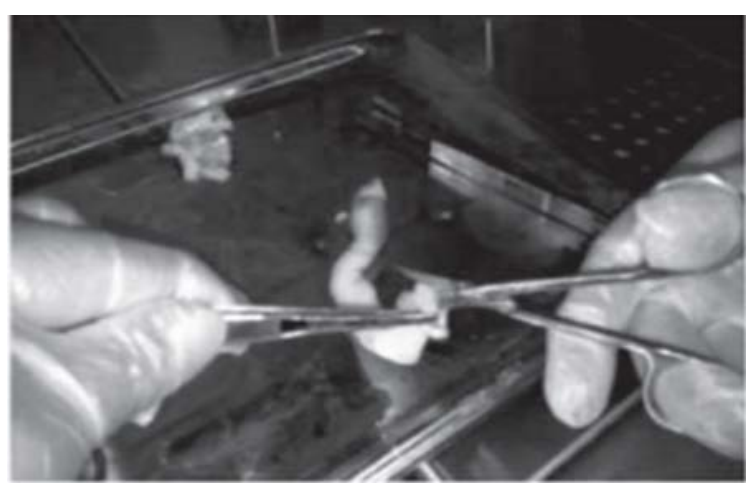

Figure 1. Segmentation of the umbilical cord from Wharton's jelly. 


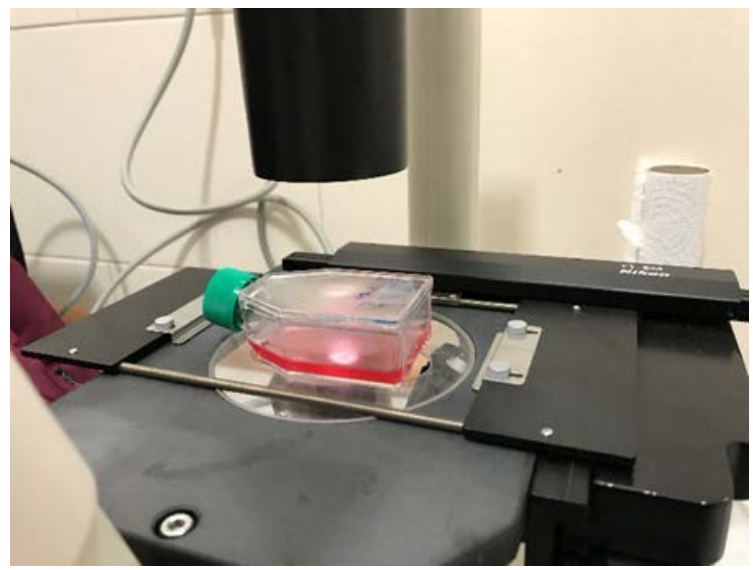

Figure 2. Examination of the sample under the invert microscope.

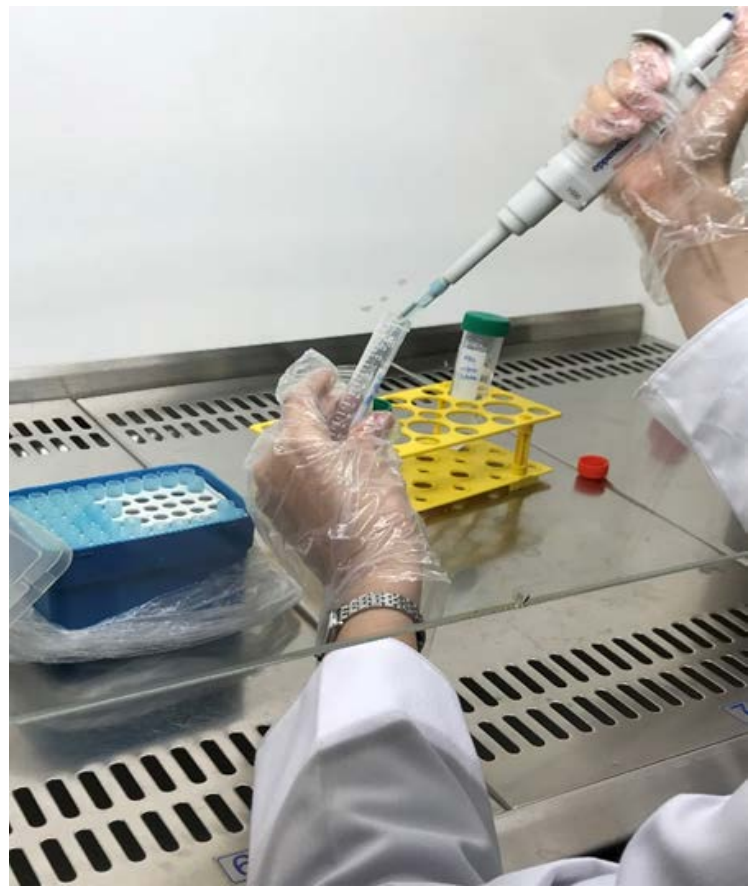

Figure 3. Prepare a suitable culture medium.

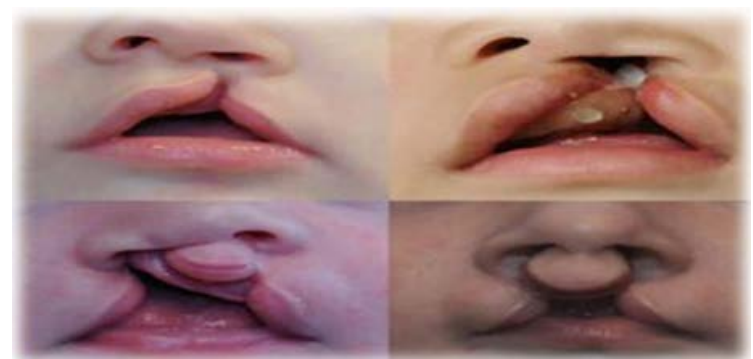

Figure 4. Procedural Treatment in Children Examined.

including the alveolar gap, now it is the usual way to treat these abnormalities by using another part of the body, such as the pelvic bone, leg or rib. It has side ef- 
fects, such as infection, walking disorders, sensory disturbances and defects in other organs. However, tissue engineering techniques have limited access to autogenous bone or a significant morbidity may occur in that place. This can be used as an alternative technique with the desired clinical success and bone formation.

\section{Conflicts of Interest}

The author declares no conflicts of interest regarding the publication of this paper.

\section{References}

[1] Bueno, D.F. (2008) New Source of Muscle-Derived Stem Cells with Potential for Alveolar Bone Reconstruction in Cleft Lip and/or Palate Patients. University of São Paulo, São Paulo, 54-58.

[2] Sadegi, S. and Zaban, A.K. (2014) Seperation, Cultivation and Identification of Mezanchimic Stem Cells Driven of Fat Tissue of Human Being. Tehran Medical Faculty Magazine, 27-32.

[3] Alviano, F., Fossati, V., Marchionni, C., Arpinati, M., Bonsi, L., Franchina, M., et al. Term Amniotic Membrane Is a High Throughput Source for Multipotentmesenchymal.

[4] Portmann-Lanz, C.B., Schoeberlein, A. and Huber, A. (2006) Placental Mesenchymal Stem Cells as Potential Autologous Graft for Pre- and Perinatal Neurodegeneration. American Journal of Obstetrics and Gynecology, 194, 664-673. https://doi.org/10.1016/j.ajog.2006.01.101

[5] Karahuseyinoglu, S., Cinar, O., Kilic, E., Kara, F., Akay, G.G., Demiralp, D.O., et al. (2007) Biology of Stem Cells in Human Umbilical Cord Stroma: In Situ and In Vitro Surveys. Stem Cells, 25, 319-331. https://doi.org/10.1634/stemcells.2006-0286

[6] Abdollahi, Z. and Mirzapoor, T. (2010) The Investigation of Stemming Cells of Mezanchimic Jelly Warton of Umbilical Cord during Distinction to Same Cells. New Cell and Mol Biotechnology Magazine, 54-58. 